\title{
ASCHFLOW - A dynamic landslide run-out model for medium scale hazard analysis
}

\author{
Byron Quan Luna ${ }^{1 *} \mathbb{D}$, Jan Blahut ${ }^{2}$, Theo van Asch $^{3}$, Cees van Westen ${ }^{4}$ and Melanie Kappes ${ }^{5}$
}

\begin{abstract}
Background: Landslides hazard analyses entail a scale-dependent approach in order to mitigate accordingly the damages and other negative consequences at the respective scales of occurrence. Medium or large scale landslide run-out modelling for many possible landslide initiation areas has been a very difficult task in the past. This arises from the inability of the run-out models to compute the displacement with a large amount of individual initiation areas as it turns out to be computationally strenuous. Most of the existing physically based run-out models have difficulties in handling such situations. For this reason, empirical methods have been used as a practical mean to predict landslides mobility at a medium scale (1: 10,000 to 1: 50,000). They are the most widely used techniques to estimate the maximum run-out distance and affected zones not only locally but also regionally. In this context, a medium scale numerical model for flow-like mass movements in urban and mountainous areas was developed.

Results: "AschFlow" is 2-D one-phase continuum model that simulates, the entrainment, spreading and deposition process of a landslide or debris flow at a medium scale. The flow is thus treated as a single phase material, whose behavior is controlled by rheology (e.g., Voellmy or Bingham). The model has been developed and implemented in a dynamic GIS environment. The deterministic nature of the approach makes it possible to calculate the velocity, height and increase in mass by erosion, resulting in the estimation of various forms of impacts exerted by debris flows at the medium scale.

Conclusions: The developed regional model "AschFlow" was applied and evaluated in well documented areas with known past debris flow events. The "AschFlow" model outputs can be considered as an indication of areas possibly affected with a defined intensity for one or more landslide events. From a user perspective the "AschFlow" model can be seen as a standalone model which can be utilized for a first assessment of potentially impact areas.
\end{abstract}

Keywords: Landslides, Run-out models, Medium scale hazard analysis, Quantitative risk assessment

\section{Background}

Medium scale analysis which include scales in the range from 1:10 000 to 1: 50000 can provide an initial overview of the hazards in a specific area. The goal of a medium scale analysis is to identify all the potentially unstable areas as accurate as possible and the down-slope regions probably affected by the flow of the failed material. This analysis should be used as a first assessment for the potential impact zones and to give an indication where further local studies should be carried out with more detail (van Westen et al. 2006). In this context, the AschFlow model was

\footnotetext{
* Correspondence: byron.quan.luna@dnvgl.com

'DNV GL, Strategic Research and Innovation at Group Technology and

Research, Høvik, Norway

Full list of author information is available at the end of the article
}

developed and implemented in order to assess the run-out behaviour of landslides and debris flows. The model was applied in two different mountainous regions (Barcelonnette Basin in France and The Valtellina Valley in Italy) with the purpose of evaluate its performance regarding the governing motion parameters and entrainment process.

\section{Literature review}

The main approaches that have been carried out in the past for a medium scale hazard analysis of landslides and debris flows can be divided by: - methods using empirical approaches, - methods using flow routing models; and - method using dynamic run-out models. 


\section{Methods using empirical approaches}

In the past, several efforts to model rapid mass movements and debris flows in mountainous environment at medium scale has been carried out successfully despite the differences between the approaches used. Miller and Burnett (2008) analyzed the regional susceptibility of debris flow using low resolution digital elevation model and land-cover data (10-m DEMs and 25-m satellite imagery) and an empirical model to determine flow paths. They calculated empirical probabilities for debrisflow run-out over DEM-determined flow paths and show how these probabilities can be combined over all sources to estimate the potential for debris-flow delivery to stream reaches throughout entire channel networks. The model was calibrated and model predictions were compared to field-mapped debris-flow travel paths from study sites in the Coast Range of Oregon, USA. Their model predicts debris-flow probability over channelreach scales that can be aggregated to basin-scale measures of debris-flow potential. Strîmbu (2011) presented a travel distance model for debris flows based on information collected in southeast British Columbia, Canada. The model incorporates a variable that represents terrain morphology by a single number. The terrain morphology was defined by a site-specific character, providing a process-based representation of local conditions. A multiple regression analysis was used to assess the dependency of even travel distance on terrain morphology, slope, stand height, terrain curvature and canopy closure. Following a similar approach, Tang et al. (2011) proposed an empirical regression model for preliminary estimates of the maximum run-out length and lateral width of debris flow on fans for the Wenchuan earthquake-affected region (12 May 2008). From a rainfall triggering event on September $24^{\text {th }}$ of 2008, 46 debris-flow catchments with well-defined debris-flow deposits on alluvial fans were selected for the analysis. To determine the variables needed for the prediction of debris flow run-out characteristics on alluvial fans, a multiple regression analysis was used to establish a statistical model for the prediction of the characteristics of debris-flow run-out zones. Their model was able to estimate debris-flow run-out zones from easily measurable topographic parameters and the availability of loose sediments in the drainage basin. From the terrain parameters used for the prediction of the characteristics of debris flow run-out zones, the volume of removable sediment was the most important factor for establishing an applicable prediction model. Conway et al. (2010) used iso-maps and associated field observations, to find a relationship between ground slope and patterns in deposition volume in the Westfjords of Iceland. They used their finding as a basis for an empirical model that enables to make an estimate of the total travel distance and final thickness of future debris flows. Toyos et al. (2008), based on the debris flow events that occurred in May 1998 in the area of Sarno, Southern Italy, presented an approach to simulate debris flow maximum run-out. Flow mobility ratios $(\mathrm{H} / \mathrm{L})$ were derived from the $\mathrm{x}, \mathrm{y}, \mathrm{z}$ coordinates of the lower-most limit of the source areas (i.e., apex of the alluvial fan) and the distal limit of the flows. They performed a regression analysis that showed a correlation between the estimated flow volumes and mobility ratios. In another important effort, Rickenmann (1999 and 2005) developed a set of empirical relationships to be used to estimate the most important parameters of debrisflow behaviour. Based on these relationships, assessment of a maximum volume can be followed by estimates of the peak discharge and the run-out distance. As mentioned before, for its simplicity, statistical and empirical models are often the preferred and a wellestablished approach when trying to assess the hazard at a medium scale (e.g., Liu et al. 2002; Castellanos 2008).

The disadvantage of using these types of empirical methods is the requirement of comprehensive and relevant datasets with defined geometrical characteristics. Another drawback of these methods is that they are not able to provide an estimate of the flow heights, velocities or pressures, which are important variables in any type of quantitative risk assessment. Besides this, if the data is taken from one single triggering event (e.g., heavy rainstorms, high magnitude earthquake) in a specific area, they are usually not representative for other areas (Tang et al. 2011). Hürlimann et al. in 2008, points out that there are several potential shortcomings when using empirical models for a risk assessment:

- They do not take into account the specific catchment characteristics that may influence dynamic behavior of the flow (e.g., topography);

- The correct selection of the future flow trajectory on the fan may be difficult to determine;

- Finding a location for the initiation point in a longitudinal profile is a cumbersome task if no other information is available;

- There is a lack of the intensity information which can only be determined indirectly, requiring additional use of other empirical relationships.

\section{Methods using flow routing models}

To avoid the shortcomings of the empirical models in terms of dimensions' simplicity and in order to take the terrain topography into consideration, two dimensional routing models (-single flow direction models, which direct flow from a starting cell to one of the eight neighboring cells based on slope gradient; and - multiple flow direction models, where the flow can invade several 
neighboring cells) have been developed and used in regional studies in the past. Scheidl and Rickenmann (2010) proposed a new method to predict the run-out of debris flows which was determined with a data base of documented sediment-transporting events in torrent catchments of Austria, Switzerland and northern Italy. They evaluated an empirical approach by correlating the planimetric deposition area with the event volume, and compared it with results from other studies. They introduced a new empirical relation to determine the mobility coefficient as a function of geomorphologic catchment parameters (reflecting some of the flow properties during the depositional part of an event). The empirical equations are implemented in a GIS-based simulation program and combined with a simple flow routing algorithm, to determine the potential run-out area covered by debris flow deposits. For a given volume and starting point of the deposits, a Monte-Carlo technique is used to produce flow paths that simulate the spreading effect of a debris flow. The run-out zone is delineated by confining the simulated potential spreading area in the down slope direction with the empirically determined planimetric deposition area. The debris flow volume is then distributed over the predicted area according to the calculated outflow probability of each cell. Scheidl and Rickenmann (2010) results confirm the semi-empirical relationship between planimetric deposition area and event volume, first proposed by Iverson et al. (1998) and applied in subsequent studies as the LAHARZ model. The LAHARZ software was developed by the United States Geological Survey (Schilling 1998). LAHARZ is a GIS code and is based on a semi-empirical model proposed by Iverson et al. (1998), which delineates lahars inundation hazard zones on a digital elevation model. The program uses two semi-empirical equations calibrated by statistical analysis of the cross-sectional area inundated and the planimetric area inundated by a lahar measured for 27 lahars deposits located at nine volcanoes in the USA, Mexico, Colombia, Canada and Philippines (Iverson et al. 1998). Using also flow routing algorithms, Huggel et al. (2003) proposed a modeling approach for a first-order assessment of hazards from glacier-lake outbursts for two lake outburst events in the southern Swiss Alps. Flow routing routines were used to simulate the debris flow resulting from the lake outburst. A multiple and a single flow direction approach were applied and the propagation was given in probability related values indicating the hazard potential of a certain location. The debris flow run-out distance was calculated on the basis of empirical data on an average slope trajectory.

One of the most recent efforts to embark upon a delineation of debris flows susceptibility maps in two dimensions for a medium scale is the software Flow- $R$ (van Westen et al. 2010) developed by Horton et al. (2013) at the University of Lausanne, Switzerland. This software uses a GIS-based approach that couples an automatic detection of the source areas and a simple assessment of the debris flow spreading (Kappes et al. 2011). Flow-R attempts to give an insight of existing or potential new susceptibility zones without any notion of intensity or occurrence probability in a regionally scale with limited data. Horton et al. (2013) applied the model Flow-R using a digital elevation model for the Canton de Vaud territory (Switzerland), a lithological map and a land use map to identify the potential source areas. The spreading and run-out estimates were based on basic probabilistic and energy calculations that allow them to define the maximal run-out distance of a debris flow. Blahut et al. (2010a) used also Flow-R for a debris flow hazard assessment at medium scale in Valtellina di Tirano, Italy. Maximum probable run-out zones were calibrated using documented past events and aerial photographs. As a result, they proposed two debris flow hazard maps: the first map delimits five hazard zones, while the second one incorporates the information about debris flow direction probabilities, showing areas more likely to be affected by future debris flows. Kappes et al. (2011) applied the Flow- $\mathrm{R}$ model to the Barcelonnette Basin in France using the model for source areas identification and the empirical angle of reach concept to define a worst-case scenario in the area. They also generated scenarios for high, medium and low frequency events, based on a varying angle of reach. The results were compared with the footprints of a few mapped events, showing a high dependency on the quality of the digital elevation model. Ma (2011) applied a method for multihazard mass movement susceptibility assessment with run-out, using Flow- $R$, in a mountainous area with limited information on past events at a regional scale in Mtsekheta-Mtianeti, Georgia. Maps with cells containing significant values of susceptibility for initiation areas were created using SMCE (Spatial Multi-Criteria Evaluation). These cells were used as initiation points and the run-out assessment was performed with the Flow- $R$ model. Based on the level of susceptibility, three different triggering scenarios were produced heuristically.

The main advantage of using flow routing models is that they are linked directly via a DEM, to the topographic characteristics of the terrain and the flow is distributed depending on the attributes of the terrain features. Flow routing models can simulate the course of the flow without a time consuming back-analysis, as no physical or pseudo-physical parameters have to be selected or defined. The disadvantages of using flow routing models are that they are highly dependent on the DEM quality and their results reflects the dependency on the accuracy of the topographical data. Flow routing 
models do not include the released mass volume of the flow; and for this reason, the intensity of the flow cannot be obtained directly.

\section{Methods using dynamic run-out models}

Past efforts working at regional scales has taken into account the flow behavior, the flow resistance and the possibility to entrain material during its course by analyzing each individual event (and its behavioral characteristics) and then imposing those characteristics for a whole region. This task can become very cumbersome for a very large area or for a single triggering event that has caused many flow events in a same area. To name some examples of this methodology, Revellino et al. (2004) used the one dimensional DAN model (Hungr 1995) to simulate the velocity and duration of debris avalanches and the distribution of the deposits in the areas of Sarno/ Quindici and Cervinara, (Italy). Using a large amount of available data (i.e., material properties and geomorphological settings), 17 cases were selected. Individual back-analysis of each case was carried out using a trial-and-error procedure and a combination of rheological parameters was found, that provided the best correspondence for each individual event in terms of run-out distance, velocity and distribution of deposits. The majority of the cases at the two sites were simulated with only one specific pair of rheological parameters (Voellmy rheology). Based on their successful simulation with closely constrained selection of input parameters, they propose to use the model to produce quite realistic first-order predictions of run-out of potential slides and to outline potential hazard areas. Another example of using physical models at medium scale is depicted by Hürlimann et al. (2006) who carried out a detailed debris flow hazard assessment in five torrent catchments in the Principality of Andorra. Using a magnitude-frequency relationship and a geomorphologic-geologic map, they were able to determine the potential initiation zones and volumes of future debris flows for each catchment. Having this information, they applied a one-dimensional physically based numerical code to analyze the defined scenarios. This was done by evaluating the critical channel sections in the fan area and the maximum run-out on the fan, resulting in intensity maps for each defined scenario and for each modeled event.

As shown before, medium scale analyses are important to pinpoint hazardous areas where the run-out of one or more landslides and debris flows can or might occur. This can give a spatial hint where more detailed studies and assessments are required in the future. At the moment, there is a lack of physically based models at the regional scale. For this, reason it was considered important to develop a medium scale numerical model for rapid mass movements in mountainous and volcanic areas. The deterministic nature of the approach should make it possible to apply it to other sites since it considers the rheological resistance and erosive characteristics of the process. Another requirement is that model can be used in an open source environment geographical information system (GIS) and should be transparent (understandable and comprehensible) to the end user.

\section{Methods and Results \\ Model description}

The developed and implemented model ("AschFlow") is a 2-D one-phase continuum model that simulates the spreading, entrainment and deposition process of a landslide or debris flow at a medium scale. "AschFlow" is based on an infinite slope model without any lateral or active-passive forces assuming that the forces are hydrostatic. The flow is thus treated as a single-phase material, whose behavior is controlled by rheology (e.g., Voellmy or Bingham). Different types of rheology are implemented within a common numerical routing scheme in the model, which will be computed from a digital elevation model (DEM). The model uses a flexible time step based on a CFL (Courant-Friedrichs-Levy) condition in order to maintain the stability of the solution throughout the simulation (Begueria et al. 2009). The model aims to create a user-friendly and practical environment while modeling by making its implementation in the open source GIS PCRaster (Karssenberg et al. 2001).

Raster maps are generated as output results after a simulation run. Three different types of maps containing information regarding the velocity of the flow, the height of the flow and the depth of the entrained material are displayed separately. Also, a raster map can be created for each time step selected in the simulation. The model also reports time series of the mass balance, time series of entrainment expressed as volume and time series of the total mobilized volume.

\section{Dynamic routines inside the model}

The model "AschFlow" distributes the flow in two dimensions $(x, y)$ with respect to the terrain topography. The flow distribution is a routing routine that is encompassed inside the near raster cells based on the gradient and the aspect of the topography. The model takes into account the change of the flow height due to the change of gradient. The bed surface gradient is calculated based on the slope of the terrain and the estimated new gradient. The aspect direction of the free surface is computed from the aspect of the new gradient. The fraction of the total material that is to be routed towards the $\mathrm{x}$ and $\mathrm{y}$ direction is determined by the computed aspect direction of the free surface.

The model is implemented in an explicit finite difference (Eulerian) mesh (i.e., the flow was described by variation in the conservative variables at points of fixed 
coordinates as a function of time (n)). The mesh is defined as a regular grid with size $\mathrm{s}=\Delta \mathrm{x}=\Delta \mathrm{y}$. The motion of the flow is determined in each time step based on the volume displaced in accordance to the height and the velocity of the flow. This displaced volume is then routed depending by the estimated fraction of the material linked to the aspect of the terrain. This routing process is highly dependent on the CFL condition for stability due to the effect of the topography in the displacement of the volume and the over- and underestimation of the flow resistance term, which typically happens in accelerating and decelerating flows. The value of the CourantLevy-Friedrichs condition is applied to the areas of the flow that are experiencing sudden changes (oscillations that can be found especially in the presence of large gradients) and have the limit values of the CFL that are specified as input parameters.

\section{Rheologies and entrainment mechanisms}

Two different rheologies are embedded as different modules inside the model representing the bed shear stress of the flow which is responsible for energy dissipation: -Bingham (Remaitre 2006) and -Voellmy (Voellmy 1955). For both rheology modules, the model calculates the driving stresses, the resistance stresses and the excess stresses according to the infinite slope equilibrium conditions.

Regarding the entrainment processes, the "AschFlow" model includes two different options to be considered depending on the type of process. These options are based on the type of entrainment rate formulation and solution that are embedded inside the model:

- Entrainment rate in terms of a change of flow height per time step (Rickenmann et al. 2003): This rate is a semi-empirical defined by a function of the mean shear stress of the flow in each time step. The rate is then controlled by the slope gradient, the volume and the density of the flow.

- Entrainment rate in terms of velocity and height (McDougall and Hungr 2005): This rate is an empirical rule of erosion velocity related to the growth rate. The growth rate is defined as the bed-normal depth eroded per unit flow and unit displacement. The volume of entrained material grows with the volume of the initial mass and velocity.

Once the entrainment rate has been computed, the model calculates a new flow height due to the scouring by adding in a cumulative manner the entrained material. The model also calculates a new soil depth based on the entrainment caused by the flow. The entrainment stops when the soil depth is zero. The model has the possibility to change the rheological parameters of the flow depending on the entrained material and the travel distance. If the flow overpasses a critical distance (defined by the user) and if entrainment occurs, the model uses the new values defined as input parameters.

\section{Model setup and initial conditions}

For the initial setup of the "AschFlow" model, three raster maps are required: i) The first raster map defines the topography of the terrain in a DEM form. This map defines not only the basal boundary of the flow, but also the spatial computation domain and the mesh size (which the DEM cell size is recommended or an interpolation is needed). No flow is allowed outside the spatial limits of the DEM. ii) The second map defines the released mass. This map delineates the spatial location, the area and the depth (thickness) of the failed material. Based on the spatial extent, the thickness of the failed mass can be variable or constant. iii) The third map defines the soil depth domain throughout the whole terrain topography. This map is relevant to delimit the amount of material that the flow can entrain.

In addition to these maps, the model requires specification of other inputs that are defined by constants; these are depending on the selected rheology. For the Voellmy rheology the inputs needed are: the turbulent coefficient, apparent friction angle, gravity acceleration, unit weight of the flow. For the Bingham rheology the model requires the following inputs: viscosity, yield strength, gravity acceleration, and unit weight of the flow. If the entrainment module is selected for a simulation, the required inputs are: the velocity scour rate coefficient or the height scour rate coefficient.

The number of time steps of each simulation has to be defined. The reporting time interval for the creation of maps must be stated, if this is not selected an end time raster map is reported automatically. In terms of the numerical stability control, the higher and lower values of the Courant-Friedrichs-Levy condition must be defined, as well as the maximum and minimum number of internal loops.

\section{Case studies}

The developed regional model "AschFlow" was applied and evaluated in well documented areas with known past debris flow events. This was done in order to test its use for medium scale debris flow susceptibility assessment. As mentioned in the introduction, two of the most recent studies in regional modeling of hazard have been done by Blahut et al. (2010a) and Kappes et al. (2011) with the Flow-R model. The results of the "AschFlow" model are compared with their results in order to evaluate the two modeling approaches and to make an assessment of the obtained modeling outputs. 


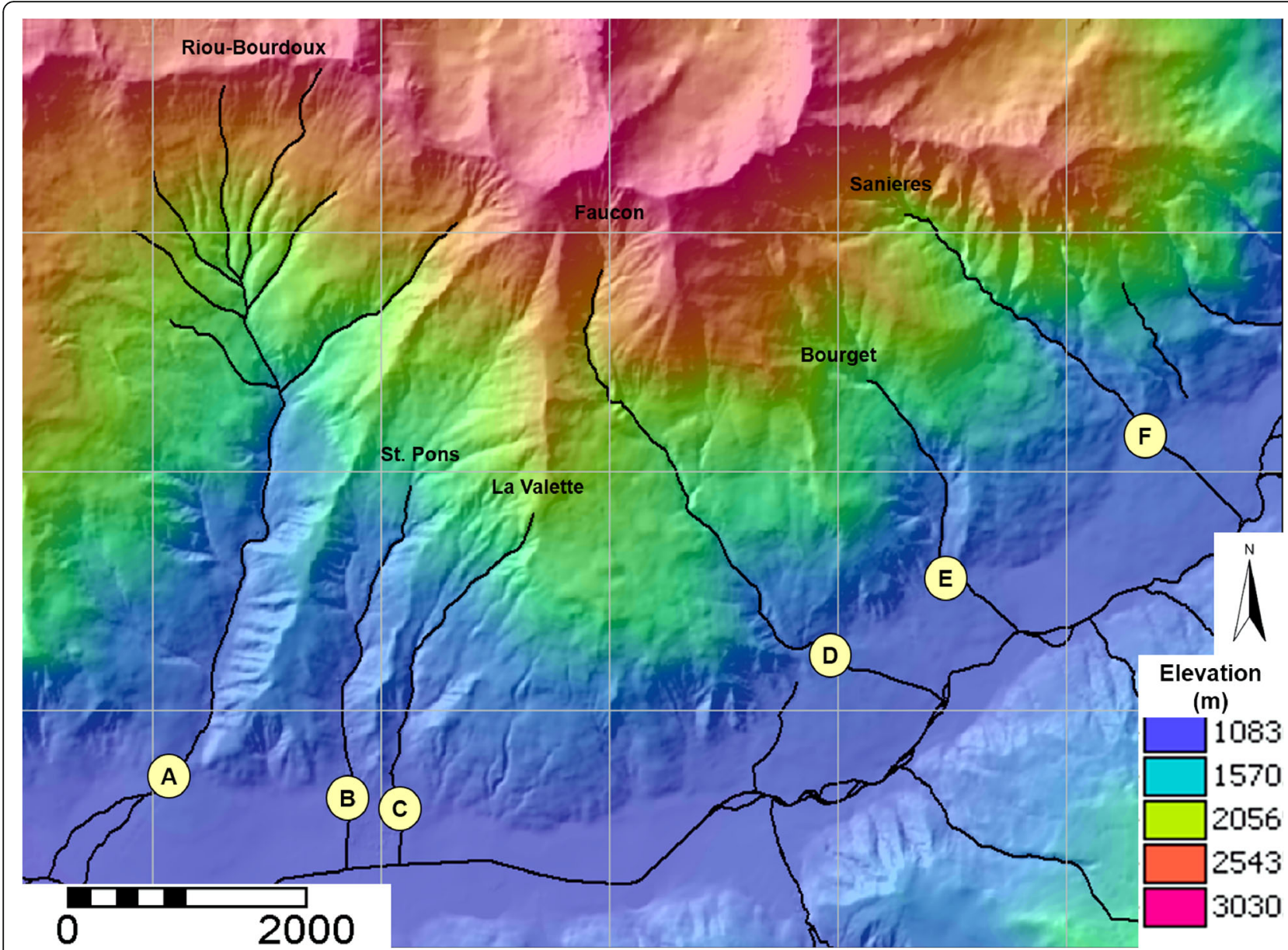

Fig. 1 Selected active debris flow streams in the north part of the Barcelonnette Basin with their respective control point at the fan

\section{Barcelonnette Basin, France}

A debris flows spatial susceptibility assessment that takes into account the intensities of impact at medium scale in the northern part of the Barcelonnette basin was performed with the "AschFlow" model. The northern part of the basin was selected because there are the most active catchments regarding debris flows and where past events have been mapped (recorded) in six major streams (Riou-Bourdoux, St. Pons, La Valette, Faucon, Bourget, Sanieres). The run-out of the susceptible initiation areas was estimated and evaluated according to past events and studies (Kappes et al. 2011). Control points were located at the beginning of each alluvial fan where the flow spreading starts and the maximum flow intensities were registered at each control point (flow height, flow velocities and flow volume with entrained material) (Fig. 1).

Most of the input data was derived from Malet (2010) and van Westen et al. (2010), which is an extensive database that contains topographic data (satellite images, a DEM with $10 \mathrm{~m}$ resolution, slope angle, aspect, plan curvature and flow accumulation), environmental factors (soil types, land use, rainfall data, lithology) and inventory data (past events information, map of catchments with frequency data of debris flows).

\section{Initiation area characterization}

The information contained in the database was used in analyzing initiation areas of events. As most of the elements at risk are located in the flood plain, on alluvial fans, and on lower slopes, the largest hazard is due to run-out of the flow, rather than to initiation (van Westen et al. 2010). For the run-out analysis source maps are required indicating areas where

Table 1 Relation between the susceptibility classes for source areas and the triggering events

\begin{tabular}{llll}
\hline Source area & \multicolumn{2}{l}{ Triggering event } \\
\cline { 2 - 4 } susceptibility class & Major event & Moderate event & Minor event \\
\hline High & 1 & 1 & 1 \\
Moderate & 1 & 1 & 0 \\
Low & 1 & 0 & 0
\end{tabular}

The value of 1 indicates that a debris flow may occur 


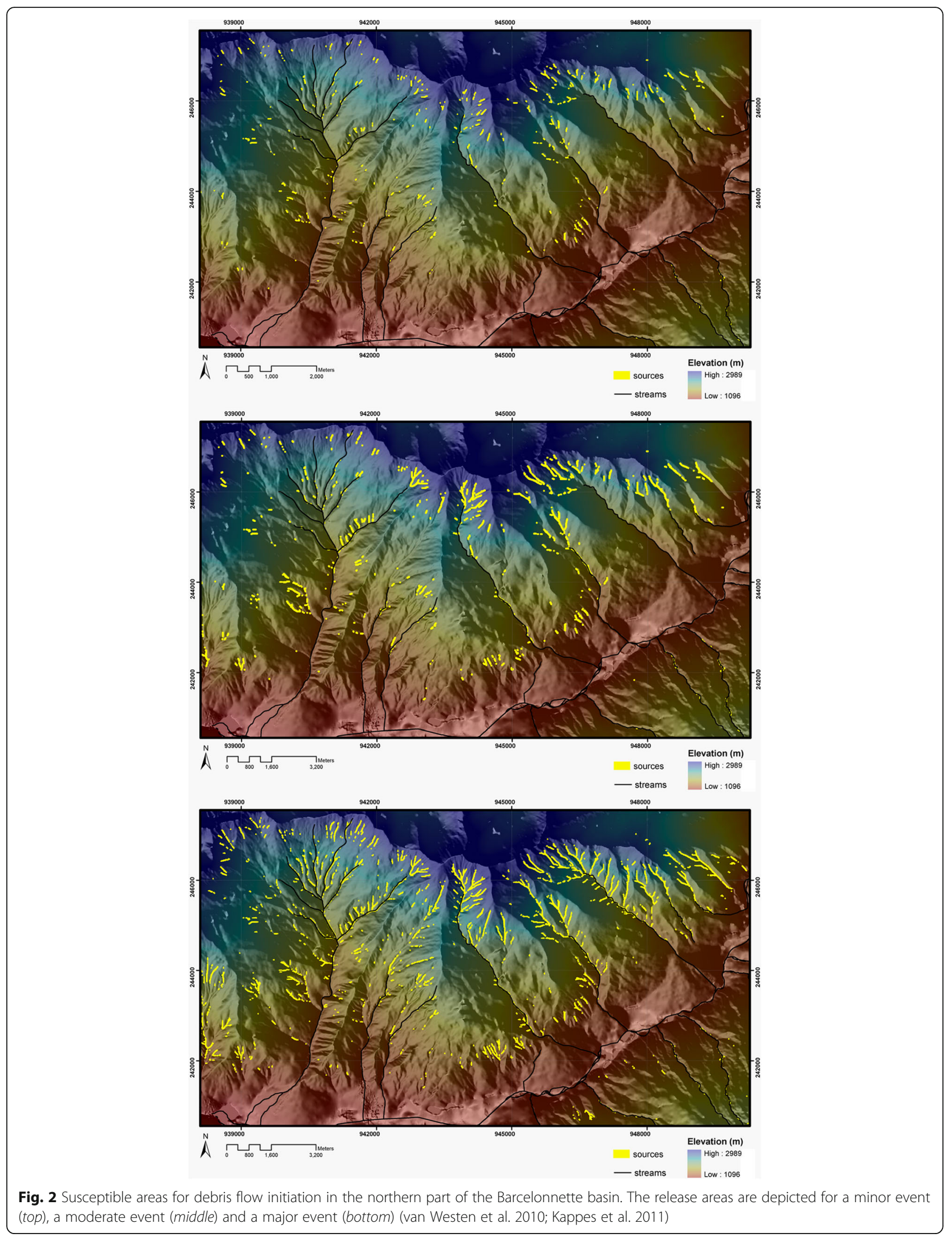


Table 2 The geometric moments of Log-normal distribution of the Bingham model were used as input parameters inside the "AschFlow" model

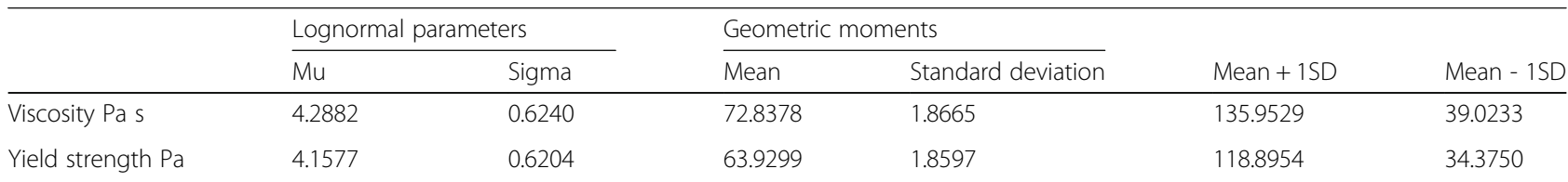

debris flows might occur. In this case study, a heuristic method was applied to assess the sources of the areas of initiation. The most relevant factor maps (land use, slope angle, plan curvature, flow accumulation and lithology) were used to generate a frequency table, in which an expert can directly indicate the expected susceptibility class (high, moderate, low or not susceptible). In order to link the initiation susceptibility to a triggering process and to be able to include this in the run-out maps, it is assumed that during a major triggering event mass movements might initiate in the high, moderate and low susceptible areas, and that a minor triggering event will trigger only landslides in the high susceptible zones. Table 1 indicates the assumptions that during a major triggering event, mass movements might initiate in all three zones (high, moderate and low susceptible areas). During a moderate triggering event, only mass movements are expected to be initiated in the moderate and high susceptible zone, and during a minor triggering event only in the high susceptible zones (van Westen et al. 2010).

This results in a series of 3 maps, indicating the presence or absence of source areas for major, moderate and minor debris flow events (Fig. 2). This susceptibility maps indicates the relative likelihood for the initiation of debris flows to be generated. The resulting maps were tested using existing data and the factors were improved using an iterative procedure until a good agreement was reached. However, there is no comprehensive landslide inventory that will allow characterizing this in detail, so it is highly based on expert opinion.

\section{Run-out characterization}

The source areas defined in the previous section were subsequently used for run-out modelling on a medium (1:25.000) scale, using the "AschFlow" model. According to lithological settings of the Barcelonnette Basin (clayshale lithology), the Bingham rheology was selected. Mud and debris flows have often been modeled as

Table 3 Intensity parameters obtained with the model (Bingham rheology)

\begin{tabular}{|c|c|c|c|c|c|c|c|c|c|c|}
\hline & \multirow{2}{*}{$\begin{array}{l}\text { Type of } \\
\text { event }\end{array}$} & \multicolumn{3}{|c|}{ Max height (m) } & \multicolumn{3}{|c|}{ Max velocity $(\mathrm{m} / \mathrm{s})$} & \multicolumn{3}{|c|}{ Max volume + entrainment (m3) } \\
\hline & & $-1 \sigma$ & $\bar{x}$ & $\overline{+1 \sigma}$ & $-1 \sigma$ & $\bar{x}$ & $\overline{+1 \sigma}$ & $-1 \sigma$ & $\bar{x}$ & $+1 \sigma$ \\
\hline \multirow[t]{3}{*}{ Riou-Bordoux Point A } & Minor & 0 & 0 & 0 & 0 & 0 & 0 & 0 & 0 & 0 \\
\hline & Moderate & 1.83 & 2.38 & 3.06 & 12.92 & 14.17 & 17.30 & 18,518 & 26,712 & 38,326 \\
\hline & Major & 4.18 & 5.71 & 6.63 & 19.10 & 21.15 & 23.73 & 36,881 & 44,553 & 51,615 \\
\hline \multirow[t]{3}{*}{ St. Pons Point B } & Minor & 0 & 0 & 0 & 0 & 0 & 0 & 0 & 0 & 0 \\
\hline & Moderate & 0 & 0 & 0 & 0 & 0 & 0 & 0 & 0 & 0 \\
\hline & Major & 0.85 & 2.33 & 3.79 & 7.44 & 14.22 & 18.55 & 8,523 & 16,211 & 19,274 \\
\hline \multirow[t]{3}{*}{ La Valette Point C } & Minor & 0 & 0 & 0 & 0 & 0 & 0 & 0 & 0 & 0 \\
\hline & Moderate & 0 & 1.22 & 1.93 & 0 & 12.47 & 17.94 & 0 & 12,572 & 15,494 \\
\hline & Major & 1.85 & 3.88 & 5.16 & 8.21 & 19.77 & 23.55 & 11,893 & 16,759 & 23,322 \\
\hline \multirow[t]{3}{*}{ Faucon Point $D$} & Minor & 0 & 0 & 0 & 0 & 0 & 0 & 0 & 0 & 0 \\
\hline & Moderate & 0 & 1.16 & 3.26 & 0 & 11.75 & 18.48 & 0 & 22,363 & 34,846 \\
\hline & Major & 3.12 & 4.98 & 7.92 & 19.44 & 22.21 & 24.55 & 55,377 & 83,013 & 127,362 \\
\hline \multirow[t]{3}{*}{ Bourget Point $E$} & Minor & 0 & 0 & 0 & 0 & 0 & 0 & 0 & 0 & 0 \\
\hline & Moderate & 0 & 0.66 & 1.15 & 0 & 12.12 & 17,41 & 0 & 9,539 & 15,253 \\
\hline & Major & 1.88 & 4.12 & 7.17 & 16.66 & 21.83 & 24.83 & 23,365 & 74,746 & 104,682 \\
\hline \multirow[t]{3}{*}{ Sanieres Point $F$} & Minor & 0 & 0 & 0 & 0 & 0 & 0 & 0 & 0 & 0 \\
\hline & Moderate & 0 & 0.74 & 1.39 & 0 & 13.42 & 17.77 & 0 & 11,772 & 18,829 \\
\hline & Major & 2.13 & 4.64 & 7.36 & 18.48 & 22.17 & 24.15 & 27,503 & 79,452 & 108,774 \\
\hline
\end{tabular}




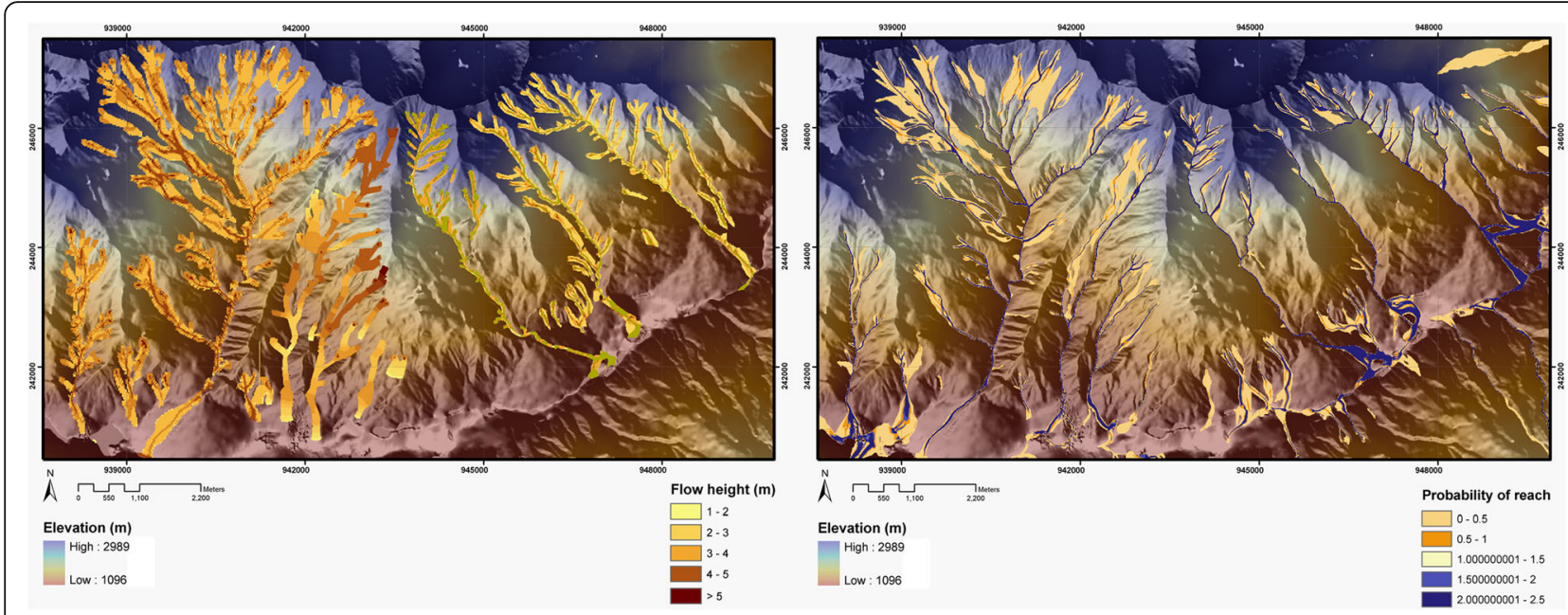

Fig. 3 Debris flow height map generated with the "AschFlow" model for the Barcelonnette basin (upper figure). Spreading reach map generated with the Flow-R model (Kappes et al. 2011) (lower figure). When comparing both maps, similarities in terms of run-out length are observable

viscoplastic materials with the Bingham rheology (Remaitre 2006). In clay-shale basins, the debris flow matrix is characterized by a high fines content and the grain-size distribution analyses of the debris-flow deposits demonstrate the muddy character of the flow (more than 20\% clay and silt). Moreover, in clay-shale basins, during the debris flow run-out, the coarse particles may be crushed. Hence the fraction of fine elements may increase during the run out. In such a case the presence of colloidal fractions may increase yield stresses (Remaitre et al. 2005a, 2005b).

Because of the lack of information regarding the behavior, the footprints and velocity distributions of past events, it was not possible to parameterize the area regarding the Bingham model with back analyses. For this reason, the moments of the Lognormal frequency distribution have been used to obtain the range of parameters for input in the model (Quan Luna et al. 2013) (Table 2). From the obtained Log-Normal distribution, the mean and standard deviation of each parameter were used to run the model for each type of event and the intensity parameters were recorded at each control point (Table 3). A homogeneous erodible soil depth of $2.5 \mathrm{~m}$ was selected since there was a lack of information about this or a soil depth map (this depth was also assumed to quantify the release volume). Based on the geological, lithological and morphological description of the area and based on the account of historical data, a soil depth of 2-3.5 $\mathrm{m}$ was found to be the value that agrees best with the quantity of entrained material in past events (Remaitre et al. 2008; Quan Luna et al. 2011, 2014). This was also done to assess the performance of the model
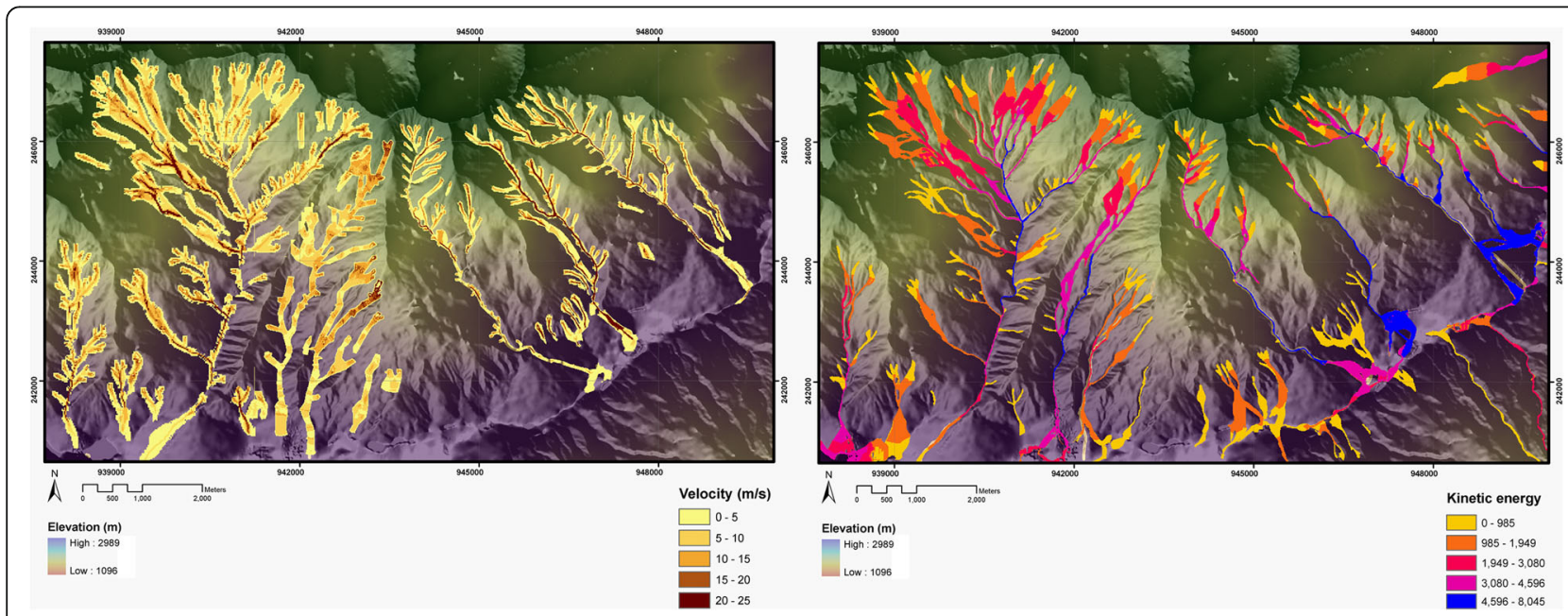

Fig. 4 Velocity map generated with the "AschFlow" model for the Barcelonnette basin (upper figure). Kinetic energy map generated with the Flow-R model (Kappes et al. 2011) (lower figure) 
when no values of soil depth can be obtained and an assumption regarding the unknown soil depth has to be done.

Regarding the computational time parameters, a time step of $1 \mathrm{~s}$ was selected and the simulations had a total time elapsed of $500 \mathrm{~s}$. For the simulation numerical stability control the values for the CFL superior limit used was 0.6 and lower limit was 0.3 with a maximum of 124 loops. Other selected parameters were: gravity acceleration of $9.8 \mathrm{~m} / \mathrm{s}^{2}$; unit weight of debris flow of $19 \mathrm{kN} / \mathrm{m}^{3}$ (selected as an average between the unit weight of a muddy flow $=18 \mathrm{kN} / \mathrm{m}^{3}$ and the unit weight of a granular debris flow $=20 \mathrm{kN} / \mathrm{m}^{3}$ ); unit weight of the soil bed of $16 \mathrm{kN} / \mathrm{m}^{3}$ (soil is assumed to be saturated). Based on the experiments of Rickenmann et al. 2003, the distance selected from the initiation point to the point where the flow starts to entrain material was $50 \mathrm{~m}$. The cut-off threshold to assume a zero velocity was $0.02 \mathrm{~m} / \mathrm{s}$. The entrainment rate selected was computed based on the velocity of the flow and height; because of the average length of the streams and the released volumes, the entrainment rate used was 0.0065 .

The spatial extent output of a "major" event simulated in the "AschFlow" model was compared with the work of Kappes et al. (2011), where the worst case modeled scenario was analyzed in the same area. Kappes et al. (2011) assessed the Flow-R model performance by means of a comparison of the potentially affected areas with the footprints of the past events. For the worst-case scenario, an enclosure of all past events into the modeled area was assumed and checked by an overlay of the area susceptible according to the model and the footprints of recorded debris flows. The Flow-R model is an empirical model that has been developed for regional susceptibility assessments using essentially a digital elevation model (DEM). The model allows

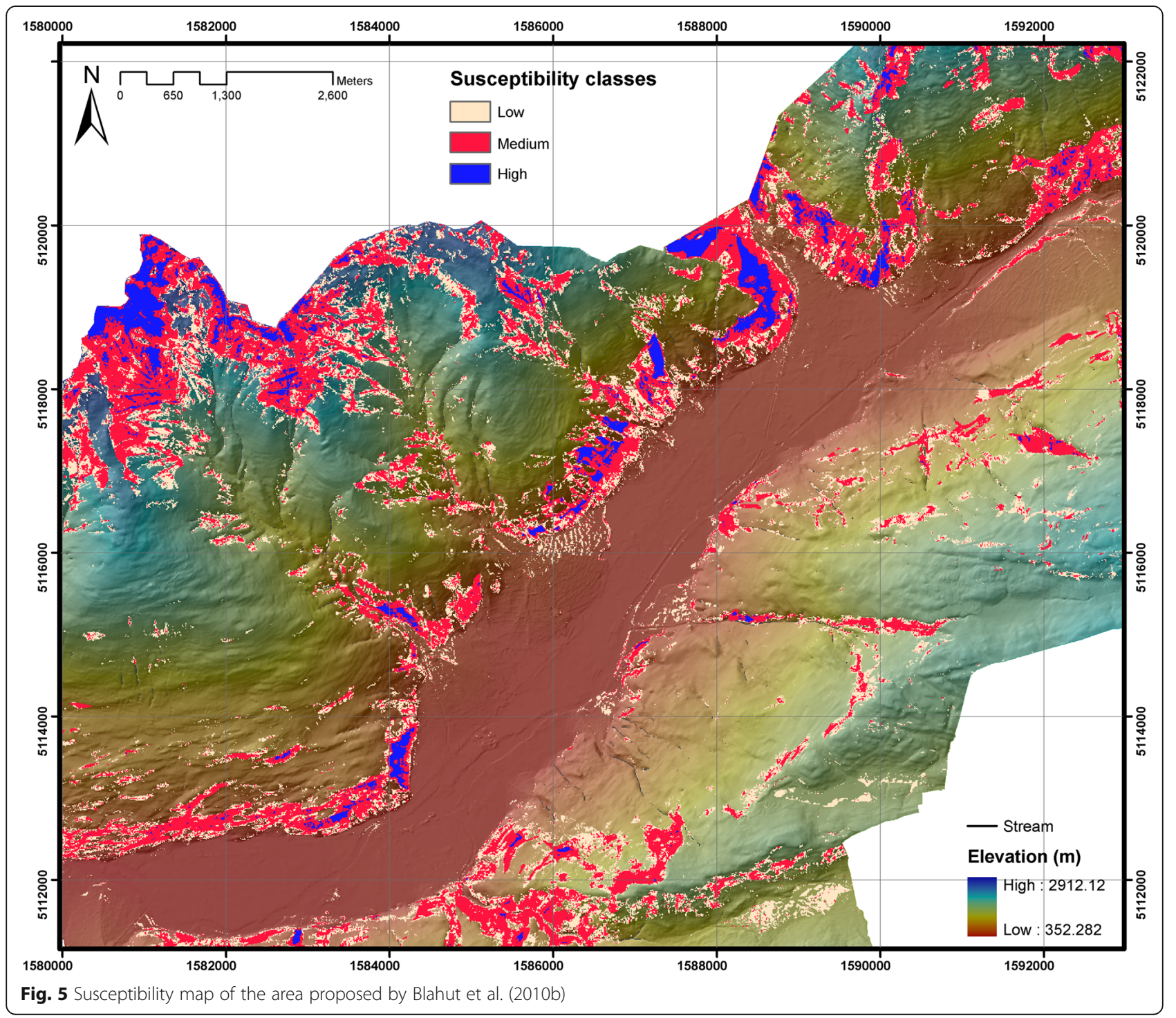


for automatic source area delineation and for the assessment of the propagation extent based on various spreading algorithms and simple frictional laws (Horton et al. 2013).

According to Kappes et al. (2011), their results are matching nearly completely past events for the slopes and the torrential fans. Minor differences are observable only for the further run-out in the flood plain of the Ubaye river. The "AschFlow" model results show agreement regarding the susceptible areas where a debris flow can occur in terms of run-out length (Fig. 3). The main difference between the two models regards the spreading of the flow. The "AschFlow" model uses a yield strength and a viscous resistance so these values can stop the flow at a critical thickness and slope angle preventing it for further spreading, which is not the case with Flow-R using probable frictional reach lines over the DTM.
Besides the differences in geometry of the flow, the "AschFlow" model generates, on the basis of calculated velocities and flow heights, intensity parameters which are important additional indicators to assess priorities for more detailed research (Fig. 4). In the case of the Flow- $\mathrm{R}$ model, the debris flow source has a certain unit potential energy (the volume is defined as a unit and cannot be specified otherwise) regarding its adjacent cells downhill. During propagation, part of this energy is lost in friction. If the kinetic energy increases reaching a maximum threshold, the energy line will have the same shape as the topography. The debris flow stops when the friction line reaches the topographical surface (Horton et al. 2013). In the "AschFlow" model the velocities are based on the slope friction of the rheological model, this means that the velocity is controlled not only by the topography but by the frictional coefficients that are

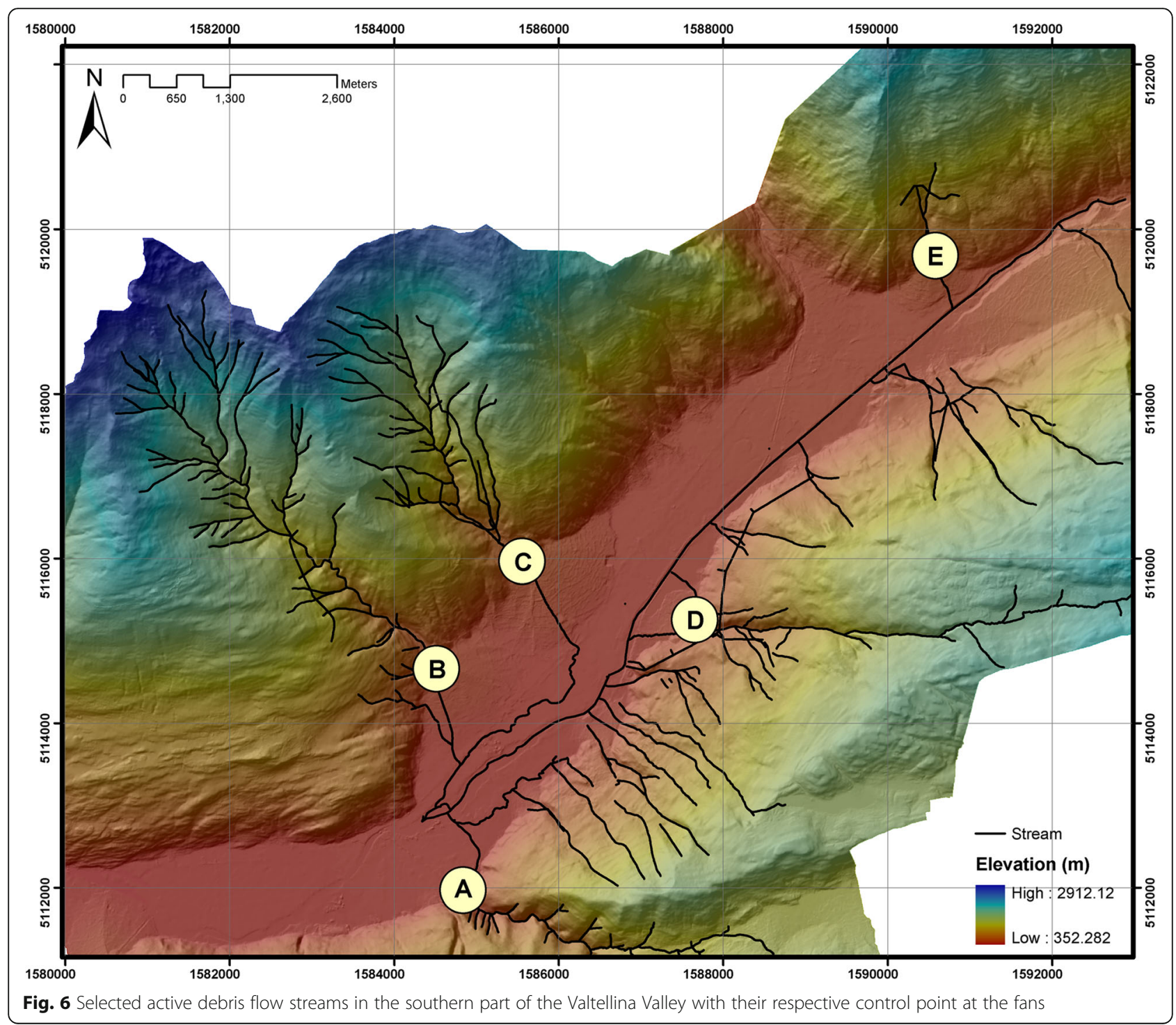


parameterized inside the model. Although it is evident that also with the AschFlow model like the Flow-R model, the determination of the source areas and the run-out assessment at a medium scale may lead to an overestimation or underestimation of the areas potentially affected.

\section{The Valtellina Valley in Italy}

A similar susceptibility assessment that was performed in the Barcelonnette area was carried out in the Valtellina Valley in Italy (for further site and historical events description, please see Blahut et al. 2012 and Quan Luna et al. 2014). In order to evaluate the other modules embedded in the "AschFlow" model, the Voellmy rheology and the entrainment rate based on the height of the flow (Rickenmann et al. 2003) was selected for the Valtellina Valley case study. The central part of the valley in the neighborhood of Tirano town was chosen for a case study because a DEM with a resolution of $5 \mathrm{~m}$ was available for that area. Another reason to select that area was the availability of an inventory of past events and a susceptibility map of initiation areas (Blahut et al. 2010a; Blahut et al. 2010b) (Fig. 5). Control points were located at the beginning of the alluvial fans where the debris flows are assumed to be most active and where the flow spreading starts (Fig. 6). Maximum flow intensities were registered at each control point (flow height, flow velocities and flow volume including entrained material). Most of the input data was derived from Blahut et al. 2010b and analyzed to compute the initiation areas.

\section{Initiation area characterization}

In the Valtellina Valley case study, relevant topographic factors were overlaid in order to get a first approach to susceptible initiation areas. Three topographic parameters slope, flow accumulation and planar curvature were complemented by lithology and a land use map. Each factor map was implemented as a raster map and thresholds for each one of them were created. A susceptible raster was considered when all the thresholds were exceeded. The threshold used for the planar curvature was: $-2 / 100 \mathrm{~m}-1$ and for the slope angle: $>15^{\circ}$. All lithological units were included except limestones, alluvial sediments, dolomite, quartzite, or peat materials. Urbanized areas, water, quarries and orchards were excluded from the land use map. Thresholds values for the terrain factors and the exclusion of units from the land use and lithological maps were chosen based on the values used by Blahut et al. (2010a) and Kappes et al. (2011). A buffer zone linked to the flow accumulation of $50 \mathrm{~m}$ was created in order to include only the susceptible points inside these areas. To assign classes to the susceptible areas, they were crossed with the susceptibility map created by Blahut et al. (2010b). This gave an indication of expected susceptibility classes: - high, -
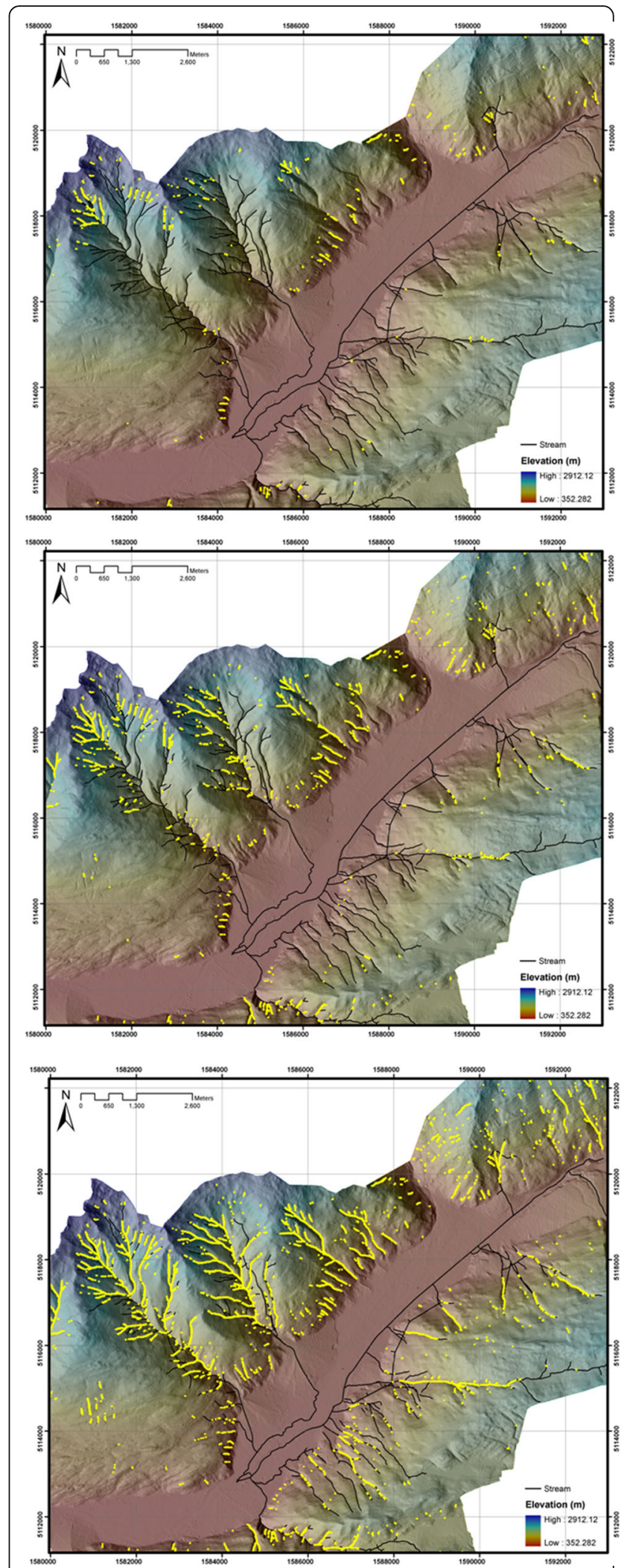

Fig. 7 Susceptible areas for debris flow initiation in the western part of the Valtellina Valley. The release areas are depicted for a minor event (top), a moderate event (middle) and a major event (bottom) 
Table 4 Log-normal distribution of the Voellmy model parameters. The geometric moments of each distribution were used as input parameters inside the "AschFlow" model

\begin{tabular}{lcccccrrr}
\hline & \multicolumn{2}{l}{ Lognormal parameters } & & \multicolumn{2}{l}{ Geometric moments } & & \\
\cline { 2 - 3 } & Mu & Sigma & & & Mean & Standard deviation & Mean + 1SD & Mean - 1SD \\
\hline Friction coefficient & -2.088 & 0.7310 & & 0.1239 & 2.0773 & 0.2573 & 0.0596 \\
Turbulent coefficient & 5.6486 & 0.6302 & & 283.89 & 1.8780 & 533.1640 & 151.1670 \\
\hline
\end{tabular}

moderate, - low. This resulted in a series of 3 maps, indicating the presence or absence of source areas for major, moderate and minor debris flow events (Fig. 7). This susceptibility maps indicates the relative likelihood for the initiation of debris flows to be generated. The resulting maps were tested using the existing inventory.

\section{Run-out characterization}

The initiation areas divided in classes that were computed in the previous section were used for run-out modelling on a medium scale using the "AschFlow" model. The Voellmy rheology was chosen in this study case to observe the model performance and its ability of another rheological model. A homogeneous erodible soil depth of $1.5 \mathrm{~m}$ was selected since there was no detailed soil depth map available (this depth was also assumed to quantify the released initial volume). This assumption was done after analyzing the descriptions of the geological and morphological characteristics of the area and past events by Cancelli and Nova (1985), Crosta (1990) and Crosta et al. (2003). In terms of the computational time parameters, as used in the Barcelonnette study case, a calculation time step of $1 \mathrm{~s}$ was selected and the simulations had a total time elapsed of $500 \mathrm{~s}$. For the simulation numerical stability control the values for the CFL superior limit used was 0.6 and lower limit was 0.3 with a maximum of 124 loops. Other selected parameters were: gravity acceleration of $9.8 \mathrm{~m} / \mathrm{s}^{2}$; unit weight of debris flow: $19 \mathrm{kN} / \mathrm{m}^{3}$; unit weight of the soil bed: 16 $\mathrm{kN} / \mathrm{m}^{3}$. The distance selected from the initiation point to the point where the flow starts to entrain material was $50 \mathrm{~m}$. The threshold to assume a zero velocity was 0.02 . The entrainment rate selected was computed based on the height of the flow, the entrainment rate used was 0.001 (Rickenmann et al. 2003).

The moments of the Lognormal frequency distribution of the Voellmy rheology were used to obtain the values of the parameters for input in the model (Table 4).

From the obtained Log-Normal distribution, the mean and standard deviation of each parameter were used to run the model for each type of event and the intensity parameters were recorded at each control point (Table 5).

Intensity parameters at each control point were recorded and also displayed in the form of maps (Fig. 8).

Table 5 Intensity parameters obtained with the model (Voellmy rheology)

\begin{tabular}{|c|c|c|c|c|c|c|c|c|c|c|}
\hline & \multirow{2}{*}{$\begin{array}{l}\text { Type of } \\
\text { event }\end{array}$} & \multicolumn{3}{|c|}{ Max height (m) } & \multicolumn{3}{|c|}{ Max velocity $(\mathrm{m} / \mathrm{s})$} & \multicolumn{3}{|c|}{ Max volume + entrainment $\left(\mathrm{m}^{3}\right)$} \\
\hline & & $\overline{-1 \sigma}$ & $\bar{x}$ & $\overline{+1 \sigma}$ & $-1 \sigma$ & $\bar{x}$ & $\overline{+1 \sigma}$ & $-1 \sigma$ & $\overline{\bar{X}}$ & $+1 \sigma$ \\
\hline \multirow[t]{3}{*}{ Point "A" } & Minor & 0 & 0 & 0 & 0 & 0 & 0 & 0 & 0 & 0 \\
\hline & Moderate & 1.58 & 2.33 & 2.74 & 6.15 & 7.89 & 9.31 & 11,357 & 23,145 & 26,388 \\
\hline & Major & 2.76 & 4.42 & 5.82 & 6.23 & 11.55 & 13.55 & 27,495 & 39,290 & 48,673 \\
\hline \multirow[t]{3}{*}{ Point "B" } & Minor & 0 & 1.05 & 1.59 & 0 & 5.22 & 5.86 & 0 & 9,050 & 11,308 \\
\hline & Moderate & 1.22 & 3.58 & 4.82 & 5.47 & 8.69 & 11.04 & 12,892 & 34,885 & 40,566 \\
\hline & Major & 3.18 & 4.74 & 5.66 & 7.17 & 10.34 & 12.28 & 36,735 & 43,932 & 56,332 \\
\hline \multirow[t]{3}{*}{ Point " $\mathrm{C}$ " } & Minor & 0 & 1.15 & 2.37 & 0 & 5.66 & 8.15 & 0 & 12,680 & 26,085 \\
\hline & Moderate & 2.05 & 4.12 & 4.78 & 8.05 & 10.17 & 11.29 & 25,460 & 39,075 & 42,536 \\
\hline & Major & 3.38 & 6.15 & 7.84 & 9.83 & 14.25 & 14.85 & 39,322 & 53,481 & 61,265 \\
\hline \multirow[t]{3}{*}{ Point "D" } & Minor & 0 & 1.80 & 2.07 & 0 & 6.10 & 8.32 & 0 & 13,045 & 19,538 \\
\hline & Moderate & 3.90 & 5.55 & 7.79 & 10.00 & 12.94 & 14.26 & 35,857 & 44,465 & 57,330 \\
\hline & Major & 4.69 & 6.96 & 9.12 & 11.16 & 14.04 & 14.90 & 42,935 & 58,027 & 74,844 \\
\hline \multirow[t]{3}{*}{ Point "E" } & Minor & 0 & 0 & 1.85 & 0 & 0 & 6.25 & 0 & 0 & 18,633 \\
\hline & Moderate & 2.31 & 3.15 & 4.22 & 6.34 & 7.57 & 9.94 & 18,755 & 23,534 & 27,700 \\
\hline & Major & 1.17 & 4.14 & 5.26 & 5.20 & 9.18 & 10.07 & 16,280 & 26,376 & 31,121 \\
\hline
\end{tabular}




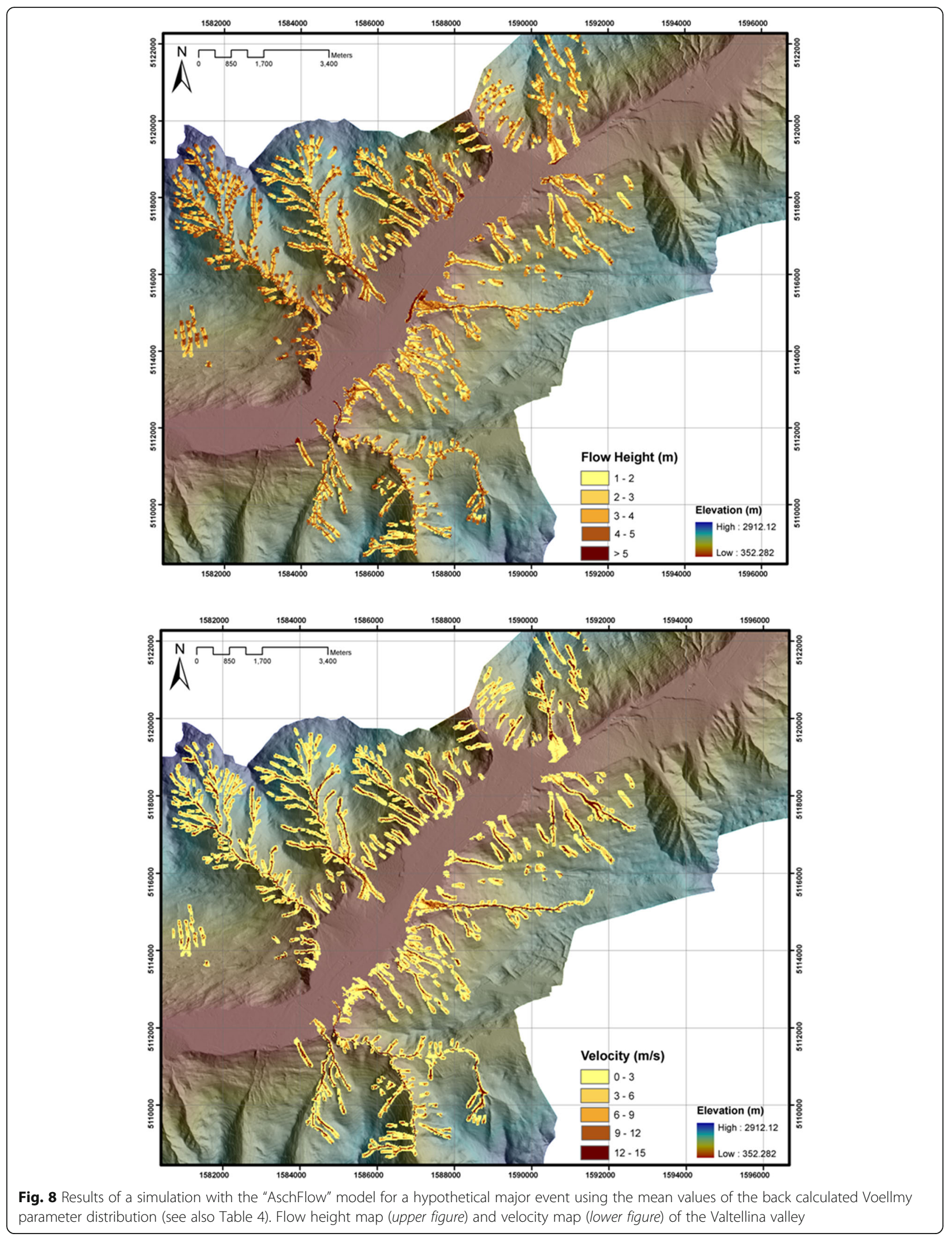


The results of the "AschFlow" model in the Valtellina Valley simulating a major event using the mean values of the distribution were compared to the geometric results of Blahut et al. 2010a where they calibrate the maximum probable debris flow run-out with the 19th July 1987 event and aerial photographs from 2001 (using the edge of alluvial fans where previous debris flows were observed). The modeled footprints obtained with "AschFlow" were compared with the modeled classes in the Flow- $\mathrm{R}$ model. As seen in the Barcelonnette case study, there is less spreading of the flow in the simulated results of the "AschFlow" model (Fig. 9).

\section{Discussion and conclusions}

One of the main purposes of a medium-scale debris-flow susceptibility analysis with the "AschFlow" model is to have a fast assessment with limited spatial information and few historical data of past events. The development of a model containing different modules for simulating flows and landslides within the framework of an open source GIS environment presents a straightforward and flexible approach. The run-out modeling process can be accomplished within a single GIS environment (PCRaster) or selected modeling steps might be accomplished outside the provided framework (i.e., initiation susceptibility maps) and then imported to the model. The "AschFlow" model is simple and fast to set up a simulation and the input parameters are easy to define. The model can serve as a tool and platform within which various modeling concepts can be tested. Because of its design it is flexible enough to work with different configurations of the initial and boundary conditions; this will allow end-users to adjust the settings of the model to a variety of situations. The inclusion of several rheological models allows easy comparison of various flow types, to choose between different types of events (e.g., hyperconcentrated or granular) and to simulate a real event as close as possible.

The result of the "AschFlow" model can be considered as an indication of areas possibly affected with a defined intensity for one or more landslide events. From a user perspective the "AschFlow" model can be seen as a standalone model which can be utilized for a first assessment of potentially impact areas.

A direct calibration of the scenarios on the basis of mapped deposition areas and frequency estimates is also possible, although not done in this study. In this context, a key limitation of the proposed model is the lack of validation concerning the calculated flow properties (i.e., height, entrainment). Future work with the model should consider the use of the model for various settings and compare the parameterization in relation to the environmental conditions. This will further validate and assure the model's quality. Information on the parameter ranges especially in regions with detailed information on volumes of past events would provide support for the calibration of the model to unknown zones. The information obtained from areas where there is sufficient information on volumes and run-out of past events can facilitate extrapolations to areas with high scarcity of data. Other versions of the model will be developed in the future which debris flow solids are generated by run-off and erosion of available loose materials accumulated in steep gullies. In these versions the severity of an event is controlled by the meteorological input, which will give information about the frequency magnitude of these events.
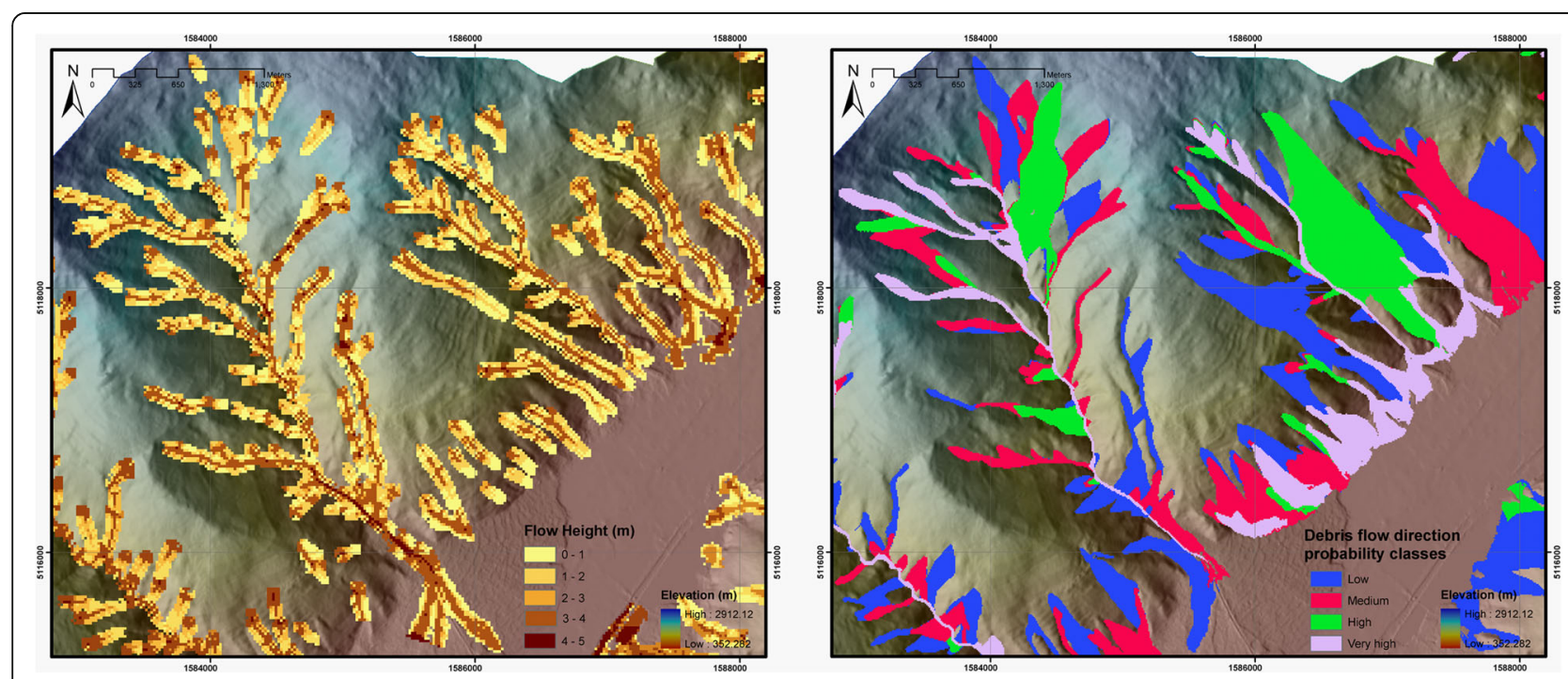

Fig. 9 Debris flow height map generated with the "AschFlow" model for a major event for the Valtellina Valley (upper figure). Debris flow direction probability classes map generated with the Flow-R model (Blahut et al. 2010a) (lower figure) 


\section{Acknowledgments}

The authors would like to thank Jean-Philippe Malet and Alexandre Remaitre for the data, their assistance and guidance during the entire process.

\section{Authors' contributions}

$\mathrm{BQL}$ and TVA developed and implemented the model. JB and MK have collected the data, run the "Flow-R" model and contributed with the manuscript. BQL carried out the simulations of the "AschFlow" model. CrW participated in the design of the study and its coordination, and conceptualize the manuscript. All authors have drafted, read and approved the final manuscript.

\section{Competing interests}

The authors declare that they have no competing interests.

\section{Author details}

'DNV GL, Strategic Research and Innovation at Group Technology and Research, Høvik, Norway. ${ }^{2}$ Institute of Rock Structure and Mechanics, Department of Engineering Geology, Czech Academy of Sciences, Prague, Czechia. ${ }^{3}$ Utrecht University, Utrecht, The Netherlands. ${ }^{4}$ Faculty of Geo-Information Science and Earth Observation, University of Twente, Enschede, The Netherlands. ${ }^{5}$ Geomorphic Systems and Risk Research Unit, University of Vienna, Vienna, Austria.

Received: 12 October 2016 Accepted: 6 December 2016 Published online: 12 December 2016

\section{References}

Begueria, S., ThWJ Van Asch, J.-P. Malet, and S. Grondahl. 2009. A GIS-based numerical model for simulating the kinematics of mud and debris flows over complex terrain. Natural Hazards and Earth System Sciences 9: 1897-1909.

Blahut, J., P. Horton, S. Sterlacchini, and M. Jaboyedoff. 2010a. Debris flow hazard modelling on medium scale: Valtellina di Tirano, Italy. Natural Hazards and Earth System Sciences 10: 2379-2390. doi:10.5194/nhess-10-2379-2010.

Blahut, J., C.J. van Westen, and S. Sterlacchini. 2010b. Analysis of landslide inventories for accurate prediction of debris-flow source areas. Geomorphology 119(1-2): 36-51.

Blahut, J., I. Poretti, S. Sterlacchini, and M. De Amicis. 2012. Database of Geo-hydrological disasters for civil protection purposes. Natural Hazards 60(3): 1065-1083. doi:10.1007/s11069-011-9893-6.

Cancelli, A., and R. Nova. 1985. Landslides in soil debris cover triggered by rainstorms in Valtellina (Central Alps - Italy). In Proceedings of 4th international conference and field workshop on landslides, 267-272. Tokyo: The Japan Geological Society.

Castellanos Abella, E.A. (2008) Local landslide risk assessment. In: Castellanos Abella, E.A.: Multi-scale landslide risk assessment in Cuba. Utrecht, Utrecht University, ITC Dissertation 154, 193-226.

Conway, S.J., A. Decaulne, M.R. Balme, J.B. Murray, and M.C. Towner. 2010. A new approach to estimating hazard posed by debris flows in the Westfjords of Iceland. Geomorphology 114(4): 556-572.

Crosta, G. 1990. A study of slope movements caused by heavy rainfall in Valtellina (Italy - July 1987). In: Cancelli, A. (Ed.): Proceedings of ALPS90, Alpine Landslide Practical Seminar - 6th ICFL International Conference and Field Workshop on Landslides, University of Milano, Milano, 247-258.

Crosta, G.B., P. Dal Negro, and P. Frattini. 2003. Soil slips and debris flows on terraced slopes. Natural Hazard and Earth System Sciences 3: 31-42.

Horton, P. M. Jaboyedoff, B. Rudaz, and M. Zimmermann. 2013. Flow-R, a model for susceptibility mapping of debris flows and other gravitational hazards at a regional scale. Natural Hazards and Earth System Sciences 13(869-885): 2013. doi:10.5194/nhess-13-869-2013.

Huggel, C., A. Kaab, W. Haeberli, and B. Krummenacher. 2003. Regional-scale GIS-models for assessment of hazards from glacier lake outbursts: evaluation and application in the Swiss Alps. Natural Hazards and Earth System Sciences 3(6): 647-662.

Hungr, O. 1995. A model for the runout analysis of rapid flow slides, debris flows, and avalanches. Canadian Geotechnical Journal 32: 610-623.

Hürlimann, M., R. Copons, and J. Altimir. 2006. Detailed debris flow hazard assessment in Andorra: a multidisciplinary approach. Geomorphology 78(3-4): 359-372.
Hürlimann, M., D. Rickenmann, V. Medina, and A. Bateman. 2008. Evaluation of approaches to calculate debris-flow parameters for hazard assessment. Engineering Geology 102: 152-163.

Iverson, R.M., S.P. Schilling, and J.W. Vallance. 1998. Objective delineation of lahar-inundation hazard zones. Geological Society of America Bulletin 100: 972-984.

Kappes, M.S., J.-P. Malet, A. Rematre, P. Horton, M. Jaboyedoff, and R. Bell. 2011. Assessment of debris-flow susceptibility at medium-scale in the Barcelonnette Basin, France. Natural Hazards and Earth System Sciences 11: 627-641. doi:10.5194/nhess-11-627-2011.

Karssenberg, D., P.A. Burrough, R. Sluiter, and K. de Jong. 2001. The PCRaster software and course materials for teaching numerical modelling in the environmental sciences. Transactions in G/S 5(2): 99-110.

Liu, X., Z.Q. Yue, L.G. Tham, and C.F. Lee. 2002. Empirical assessment of debris flow risk on a regional scale in Yunnan province, southwestern China. Environmental Management 30(2): 249-264

Ma, Y. 2011. Regional scale multi - hazard susceptibility assessment : a case study in Mtskheta - Mtianeti, Georgia, University of Twente Faculty of Geo-Information and Earth Observation ITC, Enschede, 65.

Malet, J. P. 2010. OMIV Data Access - Barcelonnette area. https://omiv.osug.fr/ data.html.

McDougall, S., and O. Hungr. 2005. Dynamic modelling of entrainment in rapid landslides. Canadian Geotechnical Journal 42: 1437-1448.

Miller, D.J., and K.M. Burnett. 2008. A probabilistic model of debris-flow delivery to stream channels, demonstrated for the Coast Range of Oregon, USA. Geomorphology 94(1-2): 184-205.

Quan Luna, B., J. Blahut, C.J. van Westen, S. Sterlacchini, T.W.J. van Asch, and S.O. Akbas. 2011. The application of numerical debris flow modelling for the generation of physical vulnerability curves. Natural Hazards and Earth System Sciences 11: 2047-2060. doi:10.5194/nhess11-2047-2011.

Quan Luna B, J. Blahut, M. Kappes, S.O. Akbas, J.P. Malet, A. Remaitre, T.W.J. van Asch, M. Jaboyedoff. 2013. Methods for Debris Flow Hazard and Risk Assessment. In T. Van Asch, J. Corominas, S. Greiving, J.-P. Malet, \& S. Sterlacchini (Eds.), Mountain Risks: From Prediction to Management and Governance, 133-177. inbook, Dordrecht: Springer Netherlands. http://doi. org/10.1007/978-94-007-6769-0_5.

Quan Luna, B., J. Blahut, C. Camera, C. van Westen, T. Apuani, V. Jetten, and S. Sterlacchini. 2014. Physically based dynamic run-out modelling for quantitative debris flow risk assessment: a case study in Tresenda, northern Italy. Environmental Earth Sciences 72(3): 645-661. doi:10.1007/s12665-0132986-7.

Revellino P, Hungr O, Guadagno F.M., Evans S.G., (2004). Velocity and runout simulation of destructive debris flows and debris avalanches in pyroclastic deposits, Campania region, Italy. Environmental Geology 45 (3):295-311.

Remaitre A. 2006. Morphologie et dynamique des laves torrentielles: Applications aux torrents des Terres Noires du bassin de Barcelonnette (Alpes du Sud). Ph. D. thesis.

Remaître, A., J.-P. Malet, and O. Maquaire. 2005a. Morphology and sedimentology of a complex debris flow in a clay-shale basin. Earth Surf. Process. Landforms 30: 339-348.

Remaître, A., J.-P. Malet, O. Maquaire, C. Ancey, and J. Locat. 2005b. Flow behaviour and runout nodelling of complex debris flow in a clay-shale basin. Earth Surf. Process. Landforms 30: 479-488.

Remaitre, A. ThWJ Van Asch, J.-P. Malet, and O. Maquaire. 2008. Influence of check dams on debris flow run-out intensity. Natural Hazards and Earth System Sciences 8: 1403-1416.

Rickenmann, D. 1999. Empirical relationships for debris flows. Natural Hazards 19(1): 47-77.

Rickenmann, D. 2005. Runout prediction methods. In: Jakob M, Hungr O (Eds.), Debris-flow Hazards and Related Phenomena 305-324. inbook, Berlin, Heidelberg: Springer Berlin Heidelberg. http://doi.org/10.1007/3-540-27129$5+13$

Rickenmann, D., D. Weber, and B. Stepanov. 2003. Erosion by debris flows in field and laboratory experiments. In "Debris-flow hazards mitigation: mechanics, prediction, and ssessment", proceedings 3rd international DFHM conference, davos, Switzerland, September 10-12, 2003, ed. D. Rickenmann and C.L. Chen, 883-894. Rotterdam: Millpress.

Scheidl, C., and D. Rickenmann. 2010. Empirical prediction of debris-flow mobility and deposition on fans. Earth Surface Processes and Landforms 35(2): 157-173. 
Schilling SP. 1998. LAHARZ; GIS programs for automated mapping of laharinundation hazard zones: U.S. Geological Survey Open-File Report, 98-638. Strîmbu, B. 2011. Modeling the travel distances of debris flows and debris slides: quantifying hillside morphology. Annals of Forest Research 54(1): 119-134.

Tang, C., J. Zu, M. Chang, J. Ding, and Q. Xin. 2011. An empirical-estatistical model for predicting debris-flow runout zones in the Wenchuan earthquake area. Quaternary International. doi:10.1016/j.quaint.2010.11.020.

Toyos, G., D. Oramas Dorta, C. Oppenheimer, M.T. Pareschi, R. Sulpizio, and G. Zanchetta. 2008. GIS-assisted modelling for debris flow hazard assessment based on the events of May 1998 in the area of Sarno, Southern Italy: II. Velocity and dynamic pressure. Earth Surface Processes and Landforms 33(11): 1693-1708.

van Westen, C.J., Th J.W. van Asch, and R. Soeters. 2006. Landslide hazard and risk zonation -why is it still so difficult? - Bull. Engineering Geology and the Environment 65: 167-184.

Van Westen, C.J., B. Quan Luna, R.D. Vargas Franco, J.P. Malet, M. Jaboyedoff, P. Horton, and M. Kappes. 2010. Development of training materials on the use of geo - information for multi - hazard risk assessment in a mountainous environment. In Mountain risks: bringing science to society : proceedings of the Mountain Risks International Conference, Firenze, Italy, 24-26 November 2010, ed. J.P. Malet, T. Glade, and N. Casagli, 469-475. Strasbourg: CERG. ISBN 2-95183317-1-5.

Voellmy, A. 1955. Uber die Zerstorunskraft von Lawinen (On breaking force of avalanches). Schweizerische Bauzeitung 73: 212-285.

\section{Submit your manuscript to a SpringerOpen ${ }^{\circ}$ journal and benefit from:}

- Convenient online submission

- Rigorous peer review

Immediate publication on acceptance

- Open access: articles freely available online

- High visibility within the field

- Retaining the copyright to your article

Submit your next manuscript at $\gg$ springeropen.com 